\title{
Constitutional Rigidity Matters: A Veto Players Approach
}

\author{
George Tsebelis \\ Department of Political Science, University of Michigan, Ann Arbor, MI, USA \\ E-mail: tsebelis@umich.edu
}

(Received 11 June 2019; revised 27 January 2020; accepted 6 July 2020; first published online 22 January 2021)

\begin{abstract}
Constitutional amendment rules have traditionally been considered the most important part of a constitution. Nevertheless, recent empirical analyses argue that constitutional amendment rules do not matter at all. This dispute is due to the misuse of independent and dependent variables and inappropriate methodology. Using the Veto Players approach to measure constitutional rigidity, this article proposes a new index covering ninety-four democratic countries. It starts by explaining the underlying logic of the veto players approach and describing the specific derivation of the rules for the construction of the rigidity index, which aggregates all institutional provisions in a logically consistent way. It then explains why the lack of constitutional rigidity is a necessary but not sufficient condition for significant constitutional amendments in democratic countries. Finally, the author creates a new dataset on the significance of constitutional amendments and estimates the appropriate (heteroskedastic) model, which corroborates the theoretical expectations and demonstrates that more significant amendments lead to a better fit.
\end{abstract}

Keywords: constitutions; amendments; veto players; constitutional rigidity; democratic countries; constitutional amendment rules; constitutional amendment significance

'...Amending clause...describes and regulates...amending power. This is the most important part of the constitution'.

(John W. Burgess, Political Science and Constitutional Law 1890, 137).

'Does the constitutional amendment rule matter at all?'

(Ginsburg and Melton (2015) Internat. Journal of Constitutional Law13(3), 686-713).

'...Amending clause...describes and regulates... amending power. This is the most important part of the constitution.'

(John W. Burgess, Political Science and Constitutional Law 1890, 137).

'Does the constitutional amendment rule matter at all?..'. Ginsburg and Melton $(2015,286)$

John Burgess (1844-1931), the former dean of Columbia University, is one of the founders of American Political Science. He dedicated four chapters of his most important book to the 'amending clause', which he argued affects 'whether the state shall develop with peaceable continuity or shall suffer alternations of stagnation, retrogression, and revolution' (Burgess 1890, 137). This understanding is echoed by Finer $(1949,127)$, who maintains that 'we might define a constitution as its process of amendment', as well as Albert $(2019,2)$, who asserts that 'No part of a constitution is more important than the rules we use to change it.'

From a normative point of view, amendment rules specify the delegation of 'the constituent power', which is 'the truth of modern democracy' since 'formulating popular sovereignty as constituent power is to affirm the basic democratic value of self-government' (Kalyvas 2012, 1). From 
a positive point of view, the constitution is the only self-enforcing contract or co-ordination mechanism in a democratic country. Democracy is impossible without such a self-enforcing contract. In Weingast's terms it is 'a focal solution [...] so that citizens gain the ability to act in concert and police their government' (Weingast 2005, 105). Amendment rules, which are defined as the meta-rules for changing the constitution, permit constitutions to evolve and incorporate necessary changes. Consequently, the level of constitutional rigidity, which is the stringency of the amendment rules, affects the ability of constitutions to evolve over time. Most analysts expect high constitutional rigidity to hinder the adoption of constitutional amendments.

However, this expected negative relationship is not strongly corroborated by empirical research. Rasch and Congleton $(2006,549)$ write, 'Clearly, there may be much more to be learned about the relationship between amendment rates and amendment procedures'. Ginsburg and Melton (GM) (2015) ask whether constitutional rules matter and look at 790 current and previous constitutions. They ultimately find that 'The institutional variables are never statistically significant and, often, they do not even have the sign one would expect' (GM 2015, 711). After finding that amendment rules have no impact on the frequency of amendments, GM (2015, 691) 'go on to develop a measure of amendment culture as an alternative to institutional factors that constrain amendment'. They conclude that their measure of political culture accounts for the frequency of amendments.

GM created an acquis communautaire among students of constitutional law. Contiades and Fotiadou (2016) consider this finding to be a correction to GM's previous analyses. They argue, 'GM by articulating this indicator of amendment culture, remedy the flaws of their earlier work and allegedly add a new parameter to constitutional scholarship' (Contiades and Fotiadou 2016, 198). Bucur and Rasch $(2019,9)$ summarize the literature as: 'A growing body of literature challenges the purely institutional understanding of constitutional change. Probably the best example for this position is the "amendment culture" argument put forward by GM (2015), according to which norms and habits are better predictors of constitutional change than the choice of amendment rules'.

Marshfield $(2018,80)$ argues that we should abandon institutional measures, and Versteeg and Zackin $(2016,661)$ echo this sentiment. Marshfield writes, 'A better measure of constitutional flexibility is a constitution's actual amendment rate because this presumably captures both the formal barriers to amendment contained in the amendment rules as well as cultural attitudes regarding formal amendment' $(2018,80)$. Versteeg and Zackin $(2016,661)$ agree and say, 'The measure [of constitutional entrenchment] does not rely on formal amendment rules because these rules are mediated so dramatically by political norms (Ginsburg and Melton 2015; Klug 2015)'. Hayo and Voigt (2016: 6) would have liked to use constitutional rigidity to calculate judicial independence but avoid it because of the GM analysis: 'Ideally, we would include a variable controlling for the formal difficulty of amending constitutions. Although some attempts to measure this difficulty have been undertaken, none of them have been completely successful. GM (2015) even propose abandoning all such attempts and looking at what they call "amendment cultures" instead'.

Tsebelis (2017a) has demonstrated that the GM analysis has both theoretical and empirical flaws. At the theoretical level, GM consider the frequency of amendments in the previous constitution as a proxy for 'culture'. Given that they are measuring the frequency of amendments in the current constitution, this variable is either irrelevant (because the previous rules are no longer applicable) or the lagged dependent variable (if one considers the constitutional history of the country). In the former case, the variable should not be included in the analysis; in the latter, including a lagged dependent variable results in the inflation of its coefficient and the

\footnotetext{
${ }^{1}$ These references to GM's cultural account of constitutional amendments are by no means exceptions in the literature. See also Bucur and Rasch (2019, 171), Dixon (2018, 812-813), Dixon (2019, 173), Dixon and Baldwin (2019, 175), Dixon and Landau (2018, 438), Dixon and McManus (2018, 596), Fruhstorfer and Hein (2016), Hayo and Voigt (2016, 6), Jackson (2016, 115), Kay (2018, 251), Landemore (2016, 90), Lorenz (2016, 731, 733-734), Marshfield (2017, 464), Marshfield (2018, 78-80), Martin (2017, 465), Merrill (2018, 568-569), Rivera (2019, 267), Sajó and Uitz (2017, 50) and Yokodaido (2019, 268).
} 
reduction of the statistical significance of other variables (which may even change the sign of the coefficient) (Achen 2001). Therefore, the GM argument at the theoretical level does not measure 'culture', and at the empirical level it produces biased coefficients (inflating the significance of the lagged dependent variable and reducing the significance of the institutional variables). ${ }^{2}$ Tsebelis (2017a) did not provide any alternative measure of constitutional rigidity and used easily available indicators for his empirical analyses (required majorities or number of institutions required to agree for a constitutional amendment).

I contribute to the literature by showing that constitutional amendment rules have a significant impact on amendment frequency. Using the veto players approach, I construct an index of constitutional rigidity, which covers ninety-four democratic countries (those that have a Polity score of 6 or above in 2013 (Marshall 2016)). Using this measure of constitutional rigidity with collected data on the significance of constitutional amendments, I find that the stringency of the amendment rule impacts the amendment frequency in a given constitution. Most of the constitutional rigidity literature only uses a subset of institutional rules and does not focus on democratic countries. Focusing on democracies is important, as these are the only countries where institutional rules are likely to apply. I also show that a segment of the literature mixes amendment rules with contextual conditions, making it difficult to assess the role of institutions. I then present a model of constitutional rigidity by explaining how to measure the core of a constitution that is, the outcomes that cannot be changed given the existing amendment rules and actors' preferences. ${ }^{3}$ The model takes all of the amendment rules into account and evaluates them only in democratic countries. In my analysis, I examine the relationship in isolation without the interaction of institutions and contextual factors to ensure future analyses can test other assumptions.

I use this model to explain the discrepancy between Burgess' expectation and the contemporary empirical research. I argue that there are three reasons that prior empirical research contradicts Burgess' arguments: (1) the independent variable is inappropriately measured, (2) the dependent variable is too inclusive and (3) the methodology used is flawed and leads to biased results.

(1) The independent variable is a proxy for the size of the core. While most authors have used similar ideas, they have not done so consistently; some analyses use only the institutional threshold while others employ the number of veto players. Still others create a composite scalar measure depending on different criteria, and none of them use a combination of all these factors along with additional time or sequence constraints (as well as the impact of alternative procedures specified by the constitution (see below)). Some scholars have adopted a different approach by using contextual and cultural variables. Previous work has analyzed a limited number of countries (around thirty) as well as all countries, regardless of how democratic they are (GM 2015). I use only democratic countries in my sample and only for the period for which they were democratic. This is an important distinction, because non-democracies do not have self-enforcing constitutions. These constitutions could be irrelevant, which means that what is happening is not the result of these constitutions.

(2) The dependent variable used in prior studies is the frequency of all constitutional amendments. ${ }^{4}$ Below I explain why amendments should be weighed by significance. I then include the variable Significance in my calculations. ${ }^{5}$

\footnotetext{
${ }^{2}$ This leaves no valid evidence about cultural, norm or unwritten institutions at the comparative level (and thus no possible comparison between 'culture' and institutions). These explanations are frequent in case studies, which is why they constitute conventional wisdom.

${ }^{3}$ This definition of a 'core' is different from the one in the law literature, which considers 'core' to be only the constitutional provisions that are not allowed to be modified at all (Albert 2015). This issue is discussed in more detail below.

${ }^{4}$ It would be more appropriate to call the variable Amendment Events, since if multiple amendments are introduced in the same year, they are considered a single amendment. This is a reasonable choice since most of the time all of them are voted in the same procedure. I follow the literature and refer to 'amendments' instead of 'amendment events'.

${ }^{5}$ From the Comparative Constitutions Project dataset. I thank Tom Ginsburg for providing the data. See below for discussion.
} 
(3) The theories provide a necessary but not sufficient condition for the frequency of amendment. Therefore, it is inappropriate to use a linear model. Advancements in methodology indicate that the necessary but not sufficient conditions lead to two different predictions: (1) on the size of the dependent variable and (2) its variance (Goertz 2017; Goertz and Starr 2002). The appropriate method treats the predicted differences in variance (heteroskedasticity) as an asset instead of a liability in the estimation. I corroborate that constitutional rigidity leads to fewer significant amendments, and show that constitutional flexibility may or may not lead to the adoption of significant amendments.

In this article, I focus on these three changes: the independent variable, the dependent variable and the methodology. I begin with a constitutional amendment theory that is designed to translate constitutional provisions (text) into measurable quantities (the core). I then derive a constitutional rigidity index, which involves translating the core into a scalar. I measure significant amendments in ninety-four countries, and empirically evaluate the relationship between significant amendments and constitutional rigidity using the appropriate methodology. The Appendices include additional explanations and information that will enable further research with different assumptions. For instance, the article presents a particular way of mapping a multidimensional object (the constitutional core) into a scalar (the constitutional rigidity index). This technique is based on a series of simplifications, which may generate reasonable objections.

In the conclusion, I argue that each of the steps I take (using the size of the core as the independent variable, using amendment significance as the dependent variable and applying the appropriate methodology (heteroskedastic regression)), and particularly their combination, strongly corroborate the century-old theoretical expectation. In the discussion, I present some additional areas in which the constitutional rigidity index can be applied.

\section{The Literature on Constitutional Rigidity}

Constitutions systematically involve two types of items (in addition to Burgess's 'most important' amending clauses): human rights and the rules of the political game, which both require time consistency. That is, human rights and the rules of the political game must be well known in advance, respected by all participants and remain constant (as long as they have not become obsolete). This is so all participants know their rights and obligations. For this reason, constitutions are designed to make modification difficult.

Constitutions include modification provisions requiring either qualified majorities of one body, concurrent majorities of several bodies or both. In addition, many constitutions specify alternative procedures for constitutional amendments. For example, some alternatives allow less stringent majorities in the legislature if the modifications are supported by a referendum. Finally, many constitutions involve provisions that cannot be modified at all, such as human rights or the broader political regime.

The multiplicity of these constitutional amendment provisions is extremely important for the way the political game is played in different countries. Stringent amendment rules can render political institutions almost 'exogenous' - as the outcome of decisions made in the past is imposed on the current players. However, if these restrictions are weak, actors will include a constitutional revision in their agenda any time the actors disagree with the constitutional rules.

There are no rules about which provisions should be included in a constitution. For example, the electoral system may be included in the constitution or not, or it may be protected by other provisions: Slovenia's constitution (Art. 80) requires a two-thirds majority to change the electoral system. In France (Art. 77), the rules concerning the electoral system are set by ordinary legislation. This is why the electoral system became the subject of political competition in 1985 (when it switched from plurality rules to proportional representation) and 1986 (when it switched back to plurality). In Greece (Art. 54), the electoral system is protected by two alternative amendment 
procedures: if the new electoral law is supported by a two-thirds majority in parliament, it is applied in the next election; if not, it 'shall be applicable as of the elections after the immediately following ones'. Because such rules are evidently consequential for the political game, students of constitutions have long studied the issue of constitutional amendment provisions under different names, including 'constitutional entrenchment', 'constitutional rigidity' (or their opposite, 'constitutional flexibility'). I use the term 'constitutional rigidity' here.

Studies of constitutional rigidity have been conducted at the normative and theoretical levels. The debate started between Jefferson, who advocated frequent changes to the constitution, and Madison, who prevailed in establishing a long-standing one. They have also been done at the empirical level, including attempts to assess the level of constitutional rigidity in different countries. Given the variety of locking mechanisms in constitutions and the founders' ability to combine them either as supplements to or substitutes for each other, creating an entirely different pathway to amendment, the range of constitutional rigidity is extremely large, which has diverse empirical conclusions.

\section{Measuring Constitutional Rigidity}

In the literature, there are two major approaches to measuring constitutional rigidity. The first uses only institutional measures, while the second combines institutional measures with others, such as the frequency of amendments and other indicators that explain this frequency. Focusing on the institutional factors alone, the level of constitutional rigidity may differ from one article of a constitution to the next. ${ }^{6}$ The constitution may provide for different provisions for the modification of different articles, such as using alternative political institutions. Similarly, it may be prohibited to amend certain articles like human rights or the regime type. Finally, there is a wide array of applicable revision procedures ranging from multiple bodies, to referendums, to time delays that sometimes involve intermediate elections, and even create special bodies, such as constitutional assemblies.

\section{Institutional Criteria}

Focusing on institutions, some authors only consider a subset of issues. For example, Lutz (1994) and Lijphart (1999) focus on the qualified majorities required in the amendment process, whereas Anckar and Karvonen (2002) focus mainly on the political actors involved (Lorenz 2005, 341-342, 344-345). Lutz (1994) studied eighty-two constitutions (the fifty US state constitutions and thirty-two countries), but Lorenz was not able to successfully apply Lutz's index to new countries (Lorenz 2005, 342). Lijphart (1999) created a fourfold typology, which divided countries based on the majority threshold required for approval. He finds that this classification correlates with the strength of judicial review (Lijphart 1999, 214-215). Schneier (2006) uses a similar method and classifies 101 constitutions into five categories and nineteen subcategories.

Other authors (for example, Elster 2000; Lane 2011) use non-voting criteria, such as time delays. Similarly, La Porta et al. $(2004,448)$ examine a group of countries whose constitutions have remained unchanged since 1980. They measure constitutional rigidity on a scale from 1 to 4 :

One point each is given if the approval of the majority of the legislature, the chief of the state, and a referendum is necessary in order to change the constitution. An additional point is given for each of the following: if a supermajority in the legislature (more than 66 per

\footnotetext{
${ }^{6}$ On the basis of this, Albert classifies constitutions as 'comprehensive' (if the whole constitution can be modified using the same rules), 'restricted' (if different provisions are subject to different rules) or 'exceptional' (where different rules are used exclusively for one provision or a set of related provisions) (Albert 2014).
} 
cent of votes) is needed, if both houses of the legislature have to approve, if the legislature has to approve the amendment in two consecutive legislature terms, or if the approval of a majority of the state legislatures is required (La Porta et al. 2004, 451).

Other authors, such as Rasch and Congleton (2006), use institutional information on formal amendment rules. They then 'create indexes of consensus and of the number of central government veto players or points of agreement required to secure a constitutional amendment' (Rasch and Congleton 2006, 546). Lorenz $(2005,346)$ focuses on a mix of institutional and contextual variables and combines elements from Lutz, Lijphart and Anckar and Karvonen to identify 'the type of majority rule with the number of voting arenas or actors'.

\section{Mixed Factors}

Turning to the combination of institutional and other factors, the most recent and sophisticated effort was undertaken by the Comparative Constitutions Project from Elkins, Ginsburg and Melton (2009). These authors start with the premise that constitutional rigidity should be calculated using a combination of the institutional procedures required for amendment and the actual frequency, or lack thereof, of amendments. According to them, each component is not sufficient on its own. While they can assess the institutional component by looking at the constitution (though with difficulties that they enumerate and that this literature review corroborates), the frequency of amendments depends on a host of social and historical factors: 'Thus, we regress the amendment rate on a set of amendment procedure variables as well as a host of factors that should predict political reform more generally, including those factors included in our model of constitutional duration' (GM 2015, 695). Such factors include percentages of different ethnic groups, economic development, amendment rate, amendment rate squared, etc. (Elkins, Ginsburg and Melton 2009, 227-228). Tsebelis and Nardi (2016) use the same indicators in their analysis. Despite this, common statements in the literature such as 'constitutional rigidity [has] a negative effect on amendment frequency' (see Lutz 1994, 365-366; Lijphart 1999, 211; Rasch and Congleton 2006, 542; Dixon 2011, 106) cannot be accurately evaluated using measures that include amendment frequency as an ingredient of constitutional rigidity. This is most likely the reason that this composite index was not used in subsequent analyses by GM (2015).

\section{Effect of Rigidity on Amendment Frequency}

Given the variety of variables included in the different indexes of constitutional rigidity, it is not surprising that there is low correlation among them (GM 2015, 698). GM find that 'only three combinations yield a correlation greater than 0.5: Anckar and Karvonen with Lijphart, Lijphart with Lorenz, and Lorenz with Lutz. The other correlations are smaller than 0.5 and correlation between the CCP and Lorenz measures is even negative' (GM 2015, 697). The fact that the rigidity indicator from the Comparative Constitutions Project is negatively correlated with other indexes implies their departure from institutional variables. GM's analysis included social, economic and other contextual indicators. In addition, as a series of authors point out, the correlation between the different measures of constitutional rigidity and amendment frequency is low (Ferejohn 1995; GM 2015; Lorenz 2005; Rasch and Congleton 2006).

There is a potential explanation for this low correlation. The institutional indexes of rigidity are based mainly on one of two methods the founders of each country used to protect the constitution: either the number of veto players (institutions or actors required to agree for a constitutional amendment) or the required majorities in each of them (Tsebelis 2017a). These methods are not independent. The founders used them in a complementary way: bicameral legislatures 
Table 1. Correlation of veto player constitutional rigidity index with other indexes

\begin{tabular}{lccc}
\hline Index & Correlation & p-value & Number observations in common \\
\hline Ginsburg and Melton (2015) & 0.09 & 0.450 & 66 \\
Anckar and Karvonen (2002) & 0.16 & 0.263 & 52 \\
La Porta et al. (2004) & 0.44 & 0.004 & 41 \\
Lijphart (1999) & 0.23 & 0.252 & 26 \\
Lorenz (2005) & 0.59 & 0.000 & 34 \\
Lutz (1994) & 0.62 & 0.001 & 23 \\
Rasch and Congleton (2006) & 0.78 & 0.000 & 17 \\
\hline
\end{tabular}

require lower qualified majorities for approval than unicameral ones. ${ }^{7}$ Depending on the weight of these two components, constitutional rigidity may take different values. As for the indexes involving other than institutional components, it goes without saying that the results will depend on the alternate variables included.

Table 1 presents the correlation among the index presented in this article and the other indexes of constitutional rigidity. It also presents the significance of the correlation ( $p$-value) and the number of observations (number of countries in common) that generate it. The overall correlations are higher than those reported in GM (2015). In particular, the correlations with the indexes of Lorenz (2005), Lutz (1994), and Rasch and Congleton (2006) who use different ways of combining institutional provisions (without covering them all) and their significance are higher, although the number of countries covered is significantly lower.

\section{From Constitutional Veto Players, to Constitutional Core, to the Constitutional Rigidity Index}

Every constitution includes a series of articles that specify the rules concerning its future revision. The rules of constitutional revision specify a series of collective or individual actors, such as one or both chambers of a legislature, a special assembly, a referendum or an elected president, that are required to agree on the revised text in order for a revision to be approved. In other words, they specify the set of constitutional veto players. In the same or subsequent articles, the constitution specifies a series of provisions, such as required quorums, majorities, time constraints as well as additional rules, such as intermediate elections, that govern the decision of each of these constitutional veto players. Constitutions often present a series of alternative mechanisms for revision - a type of system that Albert $(2014,917)$ calls 'multi-track'. If a country uses an alternative path of revision, the previously specified constitutional veto players are rescinded or quashed, either partially or completely. For example, if a constitution requires a two-thirds majority of both chambers, then these qualified majorities are veto players (their agreement is required for a constitutional revision). Alternatively, if it is necessary to have simple majorities in both chambers along with a referendum, then all three actors become veto players. Lastly, if a country (like Italy) uses either of these provisions, then neither of the two sets is required because each can overrule the other. In other words, the articles of constitutional revision both set and rescind constitutional veto players. To understand these arguments more in detail, Appendix I includes a formal interpretation of the constitutional core.

\footnotetext{
${ }^{7}$ Of the countries that require just one body for constitutional changes, 89 per cent also require a two-thirds majority or greater. Among countries that require two bodies, that percentage decreases to 63 per cent, whereas only 52 per cent of countries that require three bodies also require a two-thirds majority or greater. The most extreme countries (using only one of the two methods and generating a negative correlation) are Bulgaria and Mongolia (requiring a three-fourths qualified majority from a single chamber) and Australia, Canada, Denmark, France, Iceland, Ireland, Italy and Paraguay (requiring a simple majority for approval in three different bodies, usually including a bicameral legislature). The Appendix contains details of constitutional amendment procedures in Appendix.
} 
The Appendix provides a theoretically accurate and consistent way of calculating constitutional rigidity. This method is based on the interaction between the institutions specified in the amendment provisions of the constitution and the preferences of the relevant actors. However, the preferences depend on the subject matter of the constitutional review, and cannot be assessed a priori and in comparative perspective. Instead, I use the arguments in the Appendix to construct a simplified index based only on the amendment provisions.

I calculate the index by summing the approval thresholds of different elected institutions. This combines the veto players, who are required by the founders of the constitution, with the qualified majorities included to protect it. For all countries, the formula includes the threshold that must be reached for approval in any popularly elected body that must approve a constitutional amendment. If applicable, this formula includes: the executive (in presidential systems), the legislative, people (referendums) and regional governments. For example, if a legislative body must pass an amendment by a simple majority, 0.50 is added to the formula. If an intervening election is required between two rounds of majority approval, $0.5+0.5$ is added. For example, in Greece two votes are required by two successive parliaments (with an intervening election). One of the two majorities is three-fifths and the other is 0.50 . As a result, the basic score for constitutional rigidity in Greece is $(3 / 5+0.50)=1.10$ (see Appendix II, line 32).

For my analysis, I focus on the constitutions of countries included in the 'Constitute Project' in effect in 2013 (https://www.constituteproject.org/). I restrict my analysis to democratic countries, which I operationalize as those ranking 6 or above in the Polity Index. ${ }^{8}$

Some constitutions provide alternate paths to revision. When there are several alternative procedures, I measure only the one that is presented first in the constitution. This first path is the one the founders intended to be the primary process. For example, Italian Prime Minister Matteo Renzi could have attempted his constitutional revision either through a simple majority in both chambers and a referendum or through a two-thirds majority of both chambers. He chose the first procedure, not because it was the first mentioned procedure, but because it was easier: the proposal was significantly reducing the powers of the Italian Senate, so it would not have been accepted by two-thirds of the senators. Voters rejected the proposed amendment, so it failed anyway (Tsebelis 2017b).

Similarly, the Chilean constitution specifies three alternative ways of amendment. The intersection of the corresponding cores is an empty set (only constitution in the world, besides countries like the UK where a simple majority in Parliament is sufficient to change the constitution), but the constitutional revision of 2017 failed using the first pathway (Tsebelis 2018). If there are subsequent alternative methods, ${ }^{9}$ my index (which is calculated a priori) will include them by a small reduction of rigidity as calculated using the first method (see below). Finally, if there are different procedures for explicitly enumerated articles of the constitution, they will be ignored (different amendment procedures generate different indexes).

\footnotetext{
${ }^{8}$ These restrictions yield ninety-two countries. To these, I added Israel and the UK, bringing the number of countries to ninety-four (they are not included in Constitute because they do not have a written constitution, but they do have fundamental documents that are functionally equivalent). The choice of cut-off point is arbitrary (although six is usually used in the literature). I replicated my calculations using all the higher cut-off points $(7,8,9,10)$ and the results are robust to this change. Also, three of the countries I cover - the UK, Turkey and Taiwan - modified their amendment rule during the time covered by my study. Given that their constitution changed in the dimension I am examining here, I considered only the more recent part of their amendment history. The alternative would have been to consider these three countries as two observations each, bringing the total number to ninety-seven instead of ninety-four.

${ }^{9}$ The actual political actors in such a case will select the 'easier' method, the one that is more likely to produce the constitutional revision. The choice will depend on the policy positions of the actors involved, and cannot be included in my index.
} 


\section{Measure of Bicameral Legislatures}

Next I turn to the second chamber of a bicameral legislature. A second chamber can either be an independent majority from the lower chamber (as it has a different composition) or part of a bicameral legislature. Most constitutions designate the legislature as a required veto player and specify the required majority for approval. If the legislature is composed of two chambers, then they are usually both designated as veto players. ${ }^{10}$ I use the Euclidean distance between the two chambers as a measure of their disparity: if one legislature is composed of parties with proportions $x_{1}, x_{2}, x_{3}, \ldots x_{n}$, while in the second legislature the same parties have percentages $x_{1}^{\prime}, x_{2}^{\prime}, x^{\prime}{ }_{3} \ldots x_{n}^{\prime}$, the compositional distance between the two chambers is $\left[\left(x_{1}-x_{1}^{\prime}\right)^{2}+\left(x_{2-}\right.\right.$ $\left.\left.-x_{2}^{\prime}\right)^{2}+\left(x_{3}-x_{3}^{\prime}\right)^{2}+\ldots\left(x_{n}-x_{n}^{\prime}\right)^{2}\right]^{0.5}$, which increases as a function of the difference in the percentage that each party wins in each chamber. If the two chambers have identical compositions, which is what Lijphart $(1999,99)$ calls 'congruent', then this indicator counts them the same as a single unicameral legislature. According to this index, as the difference of the composition of the two chambers increases, constitutional revisions become significantly more difficult. ${ }^{11}$ The difference in the composition was calculated at the end of 2013. My choice implies that this difference approximates the average difference during the whole period of democratic rule in a country, which would have been a more accurate measure. For example, in Germany both chambers of a bicameral legislature have to agree on a constitutional revision with two-thirds majority. The Euclidian distance of the two chambers is 0.281 . Consequently, I calculate the constitutional rigidity in Germany as $2 / 3 \times 1.281=0.85$ (see line 30 of Appendix I).

\section{The Epsilon Rule}

To account for any modification of the rules that makes constitutional amendments more or less difficult than specified in the fundamental method, I add or subtract an epsilon (that is, a small number - in this case 0.01 ). This is done for any provision that would increase or decrease rigidity. Examples of this modification, and therefore an addition or subtraction of an epsilon, would be a provision outlining the percentage of members required for a quorum, a requirement that a revision be passed twice, a delay from one passage to the next, etc. If an alternative procedure is specified, I subtract an epsilon (see Appendix III).

This method ensures that every single rule that addresses constitutional revisions is incorporated into my measure, including any compositional differences between the two legislative chambers. What is missing is the actual ideological distance of the different parties, or other institutional veto players. $^{12}$

While these rules are applied consistently, they are not the only ones possible. For example, under the current assumptions, it makes no difference for the constitutional rigidity of a country if the parliament votes by simple majority for the amendments followed by a

\footnotetext{
${ }^{10}$ Austria is an exception; the upper chamber participates only in constitutional revisions related to federalism. South Africa's upper chamber functions similarly. Burundi requires different majorities for each of its chambers (four-fifths for the lower and two-thirds for the upper).

${ }^{11} \mathrm{I}$ have also calculated two alternative measures. One considers (weighs) all bicameral legislatures as 1.5 of unicameral ones and the other considers the $\mathrm{chi}^{2}$ distance in the composition of the two chambers. The correlations among these indices are extremely high so I only report the results of Euclidean distances alone. This method is close to Negretto's (2012) approach. He considers the effective number of parties in each legislature as creating an obstacle to the passage of constitutional reforms. All these methods use numeric approximations of spatial distributions; hence they rely on strong ceteris paribus assumptions. For Negretto, such assumptions rely on the similarity of Latin American countries. For this article, the comparison is only between the two legislatures of the same country.

${ }^{12}$ It is possible that, in a country that requires approval by a bicameral legislature and a referendum, the position of the electorate is between those of the House and the Senate; hence the electorate should not be included in the calculations since it would be absorbed as a constitutional veto player (Tsebelis 2002). Yet the formula we use here would include the referendum as an additional constraint, despite the fact that, if the measures are approved by the two houses, they would not be rejected by the referendum.
} 
referendum, or if there is a new election and the new parliament approves the amended provisions, providing the simple majorities in parliament and the referendum are required. Some might object to this simplification. The voters may have different preferences than a subsequent parliament, and it is not obvious which one of them is closer to the positions of the initial parliament. However, the constitutional rigidity index would be calculated as: $0.5+$ $0.5=1$ in both cases. Similarly, it makes no difference in the index if a double passage by the same parliament is required or if there is a quorum requirement. Both cases require adding an epsilon to the indicator. For more clarification, the reader can refer back to Greece and Germany in lines 32 and 30 of Appendix I. For Greece, I add an epsilon, because of two votes required in the first reading, and an epsilon subtracted because of the two alternative procedures. This leaves the index unchanged at 1.10. For Germany, I add an epsilon to represent the requirement of two-thirds of the total number of members of the chambers (and not of the members present); the final result for Germany is 0.864 . These choices are the simple application of the rules outlined above. ${ }^{13}$

Empirically, the constitutional rigidity indicator is negatively correlated with the frequency of constitutional amendments in all the current constitutions of democratic countries as of 2013. This is an indirect validation of the index. These countries are a subset of GM's (2015) data on amendment frequency: GM (2015) cover up to 790 constitutions of all countries, regardless of their democratic status. They include multiple constitutions per country, but I only consider the constitutions in effect in 2013 and the constitutional history of countries only when they are democratic. If a country falls below 6 in the Polity index, the corresponding years are eliminated. Given that I use the rate of amendment years over the total democratic years, eliminating a year may affect the numerator of my variable (number of amendment years) but will certainly affect the denominator (total number of democratic years). ${ }^{14}$ These restrictions leave a sample with a wide range of both constitutional rigidity and constitutional amendment frequency. The range of the constitutional rigidity scale extends from 0.5 to 1.51 with a standard deviation of 0.27 . These numbers roughly correspond to 1-3 different veto players with simple or qualified majorities. An intuitive way of understanding this measure is to say that a change of two standard deviations is roughly equivalent to adding a referendum or the approval of a popularly elected president as a requirement for the validity of a constitutional amendment. With respect to amendment frequency, the range is from 0 (no amendments in any democratic year) to 1 (amendments passed in every democratic year). The average constitutional rigidity in the sample is 0.88 and the average amendment frequency is 0.28 amendments per year (that is, an amendment every four years).

Figure 1 presents the relationship between the two variables, which shows a negative slope between restrictive amendment rules and amendment frequency. When amendment frequency is regressed against veto player constitutional rigidity, the standardized results produce a negative coefficient of -0.335 with a p-value of $0.0003 .{ }^{15}$ The significance of these numbers is that a one-standard-deviation increase in constitutional rigidity is associated with one-third of a standard deviation decrease in amendment frequency. ${ }^{16}$ Also, adding a referendum requirement will

\footnotetext{
${ }^{13}$ For the researchers who do not share my assumptions and simplifications, Appendix I provides the necessary information to alter them and produce a different indicator of constitutional rigidity.

${ }^{14} \mathrm{I}$ also drop amendments from the sample if the individuals coding the significance of these amendments agreed that there was no amendment in a given year. This occurred in the following cases: Austria 1954, Cape Verde 1992, Czech Republic 2013, El Salvador 2003, Guatemala 1986, Honduras 2012 and 2013, Latvia 2013, Luxembourg, 1988, Malaysia 1959 and 1961, Nicaragua 1994, and Switzerland 2007 and 2011. In Nepal, there was an amendment in 2012 that was missing from the data. Given that out of 866 classified amendments only 15 cases of disagreement were identified, the Ginsburg and Melton (2015) amendment data are very reliable. The Appendix II contains a complete list of amendments.

${ }^{15} \mathrm{~A}$ linear regression gives a coefficient of -0.336 (with the same p-value).

${ }^{16}$ This is just over 0.06 amendments per year
} 


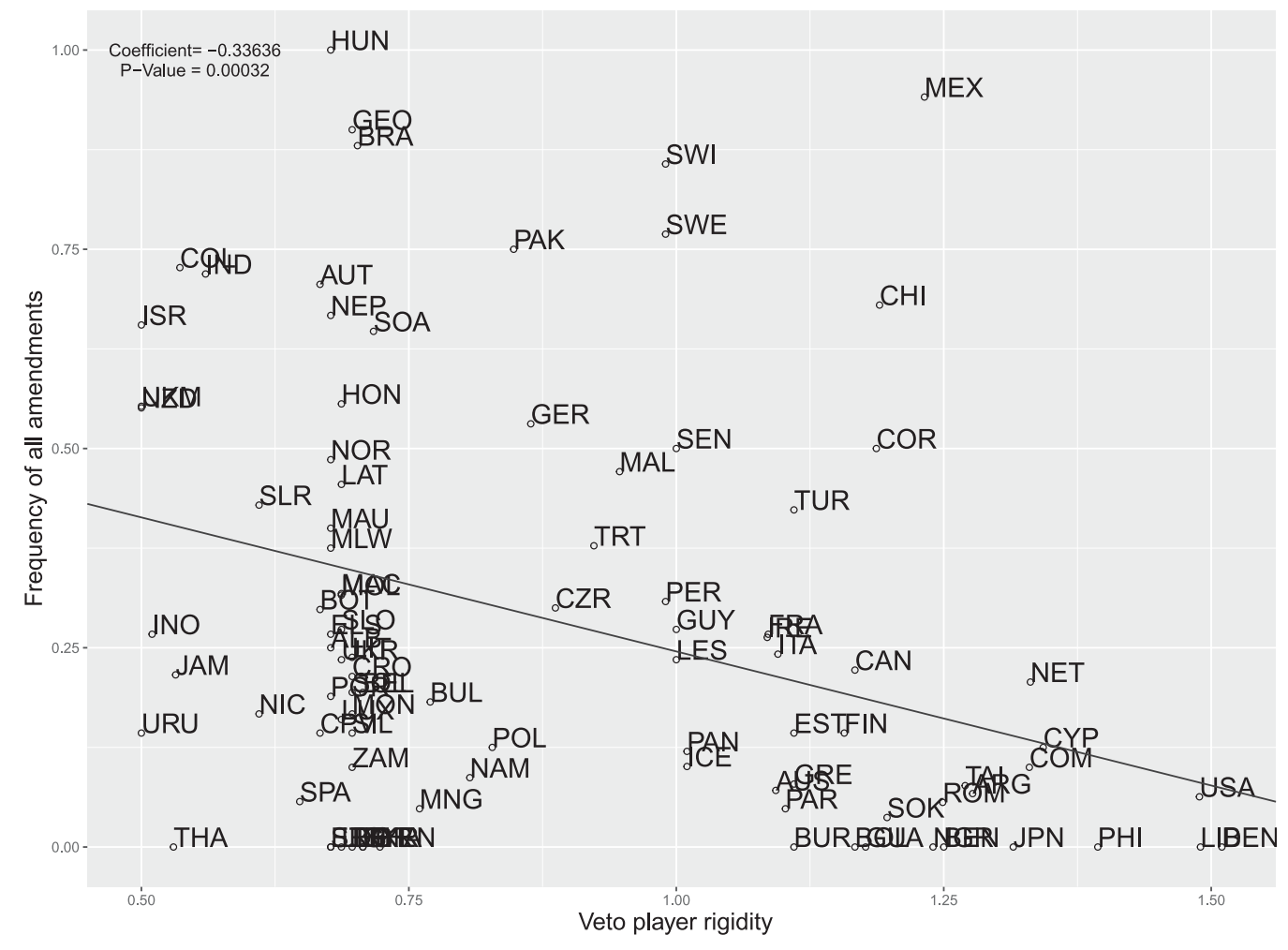

Figure 1. VP rigidity and amendment frequency

decrease amendment frequency by half a standard deviation. In other words, adding a referendum requirement halves the amendment rate in eight years. So, the answer to the question that GM (2015) ask: 'Does the constitutional amendment rule matter at all?' is a resounding 'yes' for democratic countries. I underline 'democratic' because one reason for the discrepancy in the findings (besides the ones referred to in the introduction) may be that the inclusion of nondemocratic countries in the GM dataset leads to the analysis of constitutional features that are not respected, and consequently irrelevant.

This first result, shown in Figure 1, corroborates most of the literature's expectations, including Burgess'. However, I will show that this is only part of the story. In the remainder of the article, I will demonstrate that there are two more reasons that will increase the fit of the empirical analysis. The first is theoretical, and the second empirical. The theoretical reason is that because the lack of constitutional rigidity is a necessary but not sufficient condition for the existence of amendments, my predictions will cover not only the relationship between constitutional rigidity and the frequency of amendments, but also the negative effect of constitutional rigidity on the variance of this relationship. This means that I will include heteroskedasticity in both the theoretical predictions and the empirical tests (Figure 1 already provides the visual impression of heteroskedasticity). The empirical improvement is that the expectations should become more accurate the more significant the amendments. For this purpose, I will create a new dataset on the significance of constitutional amendments, and demonstrate that the theoretically expected relationship will be more pronounced the more significant the amendments. 


\section{Constitutional Amendment Theory and Tests}

In the second part of Appendix I, I present the argument that constitutional rigidity is a necessary but not sufficient condition for the absence of constitutional amendments. Indeed, a country with constitutional flexibility does not need to modify its constitution frequently. As a result, the relationship between constitutional rigidity and amendment frequency will be heteroskedastic: at high levels of constitutional rigidity amendments will be infrequent, or even impossible, while at low levels of constitutional rigidity, amendments are possible but their frequency will be high or low depending on other conditions (for example, political actors may not be willing to change the status quo, despite the fact that it is easily amendable). The result of this argument is that the appropriate procedure to test the theoretical expectations is not a linear regression (as used in all of the previous empirical literature) but a heteroskedastic regression, which is used to make predictions not only about the average value of the amendment frequency, but also about its variance.

One more variable is expected to have an important impact on the relationship: the significance of amendments. This article presents a rational analysis of the relationship between amendment difficulty (constitutional rigidity) and amendment frequency. This relationship will be more accurate the more significant the amendments. For more significant amendments, the actors will make more elaborate and accurate calculations and probably will not undertake them if they think they may fail; even if they do, they are unlikely to succeed given the difficulty of achieving the goal. This expectation regarding significant amendments is congruent with the findings on legislative output both in the United States (federal and state levels) and from a comparative perspective. For example, Howell et al. (2000) divided federal legislation into three categories: landmark, significant and trivial. They find that while a divided government depresses the production of landmark legislation by about 30 per cent, it has no substantive effect on the production of important, albeit not landmark, legislation and a positive effect on the passage of trivial laws (Howell, et al. 2000). In a study of policy making in state legislatures, Crosson (2019) measures the size of the legislative core and finds substantively larger results when accounting for bill significance. Finally, Tsebelis (2002) divided legislation in European countries into two categories, and found that veto players and their distance are negatively correlated with the production of significant legislation but not with the production of non-significant pieces of legislation.

In conclusion, I expect to find a negative heteroskedastic relationship between constitutional rigidity and amendment frequency, which will be more pronounced as the amendment's significance increases. To test this relationship, I measure the level of significance of the constitutional amendments in my sample. I designed a survey that organized the constitutional data from GM by country. In this way, country experts can evaluate the significance of all of the amendments in their countries of expertise (Ginsburg and Melton 2015). I posted the survey link on the constitutional law blog I-CONnect ${ }^{17}$ in addition to personally reaching out to a range of people from lists of country experts. The questionnaire presented a three-class typology of amendment significance:

- Category 3 includes 'amendments of exceptional significance' that, at the time of passage, transformed the understanding of at least one area of the country's constitution. Amendments in this category transform how legislative bargaining or interbranch relations transpire, introduce an entirely new class of individual rights to a citizenry, or were subsequently deemed 'unconstitutional' by the country's Supreme Court.

- Category 2 includes 'significant amendments', meaning changes that added or modified an important aspect of the constitution. These amendments alter (but do not transform) key institutional features of the legislative, executive, or judicial bodies of government (or their relationship); expand the electorate (but not fundamentally alter it) in some way; or enhance individual rights.

\footnotetext{
${ }^{17}$ http://www.iconnectblog.com/2017/10/constitutional-amendment-significance-a-survey/.
} 
- Category 1 is the residual category of 'not significant, or insignificant amendments'. Given that the bar is very high for Categories 2 and 3, most amendments belong to this residual category.

The survey elicited multiple sets of answers for numerous countries (from one to six). ${ }^{18}$ Where there were discrepancies between sets of ratings, I used the median rating. ${ }^{19}$ If the median was not an integer but an interval (a possibility with two or four responders), I used the more conservative estimate (the lower of the two numbers).

\section{Constitutional Rigidity and Significance of Amendments: A Negative Heteroskedastic Relationship}

I use these data on the significance of constitutional amendments to test the relationship between constitutional rigidity and amendment frequency. I argue that this relationship will have three dimensions:

(1) On average, the frequency of amendments will decline with constitutional rigidity.

(2) The variance of the relationship will decline with constitutional rigidity.

(3) The significance of the relationship will increase as a function of the significance of amendments.

I use a heteroskedastic regression model to test these predictions. Heteroskedasticity is generally considered a liability in empirical estimations, because it reduces the reliability of coefficients. My analysis predicts heteroskedasticity, so having a heteroskedastic relationship should not be seen as a liability. I expect a negative relationship between constitutional rigidity and the frequency of amendments, as well as on the variance of this frequency. I also expect to find more significant results when the amendments are more significant. Appendix IV describes the nine models, which I use to present the essence of my argument in Table 2.

The table examines three categories of significance: (1) all of the amendments (Categories 1, 2 and 3 in Appendix II), (2) the more significant ones (Categories 2 and 3) and (3) the most significant ones (Category 3). For each category, three regressions are performed: the null model (assuming no relationship between constitutional rigidity and frequency), the linear model (assuming a linear but not heteroskedastic relationship between constitutional rigidity and the frequency of amendment), and the heteroskedastic model (assuming a negative effect of rigidity on both the frequency of constitutional amendments and the variance of this frequency). In all three cases, I produce the added explanatory value of each model by reporting the p-values from a likelihood ratio test comparing the specified models.

Table 2 underlines three main points. First, as predicted, the coefficients of constitutional rigidity are negative for both the mean frequency and the variance of this frequency. Second, for each level of amendment significance the model's explanatory power increases from null, to linear, to heteroskedastic; the contribution of the mean or the variance varies for different levels of significance (for all amendments $(1+2+3)$ the changes of frequency provide the main part of the explanatory power of the model, while for more significant $(2+3)$ or fundamental (3) amendments most of the explanation is provided by the variance). Finally, and most important, the added value, denoted by the highlighted p-value of the difference between the null model and the heteroskedastic model, increases with the significance of the amendments,

\footnotetext{
${ }^{18}$ I scored the countries for which I received no answer after several attempts.

${ }^{19}$ Unless the answers indicated a violation of the instructions. For example, all amendments approved on the basis of constitutional rules, but rejected by the Constitutional Court on the basis of substance (not procedure), were classified as 3 , since (on the basis of the court's judgment) they were unconstitutional.
} 
Table 2. Comparison of three models of effects of constitutional rigidity (null, mean only, and heteroskedastic) on amendment frequency (likelihood ratio tests)

\begin{tabular}{|c|c|c|c|c|}
\hline Significance categories & Models & $\begin{array}{c}\chi^{2} \\
\text { statistics }\end{array}$ & p-values & Observations \\
\hline \multirow[t]{3}{*}{ Frequency of All Amendments } & Null model vs. Mean-only model & 8.35 & 0.0039 & 94 \\
\hline & $\begin{array}{l}\text { Mean-only model vs. Heteroskedastic } \\
\text { model }\end{array}$ & 1.42 & 0.2328 & 94 \\
\hline & Null model vs. Heteroskedastic model & 9.78 & 0.0075 & 94 \\
\hline \multirow{3}{*}{$\begin{array}{l}\text { Frequency of Major + Fundamental } \\
\text { Amendments }\end{array}$} & Null model vs. Mean-only model & 5.67 & 0.0173 & 94 \\
\hline & $\begin{array}{l}\text { Mean-only model vs. Heteroskedastic } \\
\text { model }\end{array}$ & 10.51 & 0.0012 & 94 \\
\hline & Null model vs. Heteroskedastic model & 16.18 & 0.0003 & 94 \\
\hline \multirow[t]{3}{*}{ Frequency of Fundamental Amendments } & Null model vs. Mean-only model & 3.21 & 0.0731 & 94 \\
\hline & $\begin{array}{l}\text { Mean-only model vs. Heteroskedastic } \\
\text { model }\end{array}$ & 62.18 & 0.0000 & 94 \\
\hline & Null model vs. Heteroskedastic model & 65.39 & 0.0000 & 94 \\
\hline
\end{tabular}

moving from 0.008 for all amendments, to 0.000 for significant and fundamental amendments, and 0.000 for fundamental amendments. In other words, the relationship between constitutional rigidity and the frequency of constitutional amendments is heteroskedastic, as predicted, and the significance of this relationship increases with the significance of amendments under consideration. This new finding is consistent with the findings of the literature on legislation.

\section{Conclusions}

I started my analysis with a puzzle generated by the mismatch between the theoretical literature and empirical results on the importance of constitutional amendments. The theoretical literature considers constitutional amendment rules to be of paramount importance. However, previous empirical analyses have generated mixed results, and take the 'no impact' assessment for granted.

To resolve this puzzle, I slightly modified the theory. Instead of the standard argument 'constitutional rigidity reduces amendment frequency', I claim that 'institutional rigidity is a sufficient but not necessary condition for low amendment frequency'. In order to make a theoretically informed empirical analysis, I used the veto players approach to construct the core of the constitutions of all democratic countries (arguments presented in Appendix I), and reduced it to an index of constitutional rigidity calculated on the basis of veto players (presented in Appendix II). The reasoning behind the index is not different from other variables in indexes, except I included all constitutional provisions, and I applied them in a consistent way. I only run the analysis on the set of democratic countries for the periods they were democratic. Researchers cannot use constitutional constraints to explain behavior when the constitution itself is not respected. Finally, using an expert opinion survey, I constructed a variable to denote the importance of amendments. For the empirical analysis, I used the appropriate heteroskedastic regression and concluded that the more significant the amendments, the more my expectations were corroborated.

Constitutional rigidity affects the frequency of significant amendments in the following ways: high rigidity makes amendments rare, but low rigidity simply enables amendments, which may or may not occur, depending on political, social or economic factors. As a result, low constitutional rigidity produces a higher average rate and higher variance of significant constitutional amendments. The higher the significance of amendments, the stronger the above relationship. This evidence corroborates Burgess' statement that opened this article and demonstrates why the heteroskedastic data (which are necessarily noisy), if not analyzed correctly, lead to misleading and unwarranted conclusions that constitutional amendment rules do not matter at all and should either be replaced by cultural explanations (Ginsburg and Melton 2015) or completely ignored (Versteeg and Zackin 2016). 
In this article I demonstrated the intrinsic value of constitutional rigidity: how and why it affects amendment frequency. However, constitutional rigidity also affects other variables, such as the survival of the constitution, the time inconsistency of the constitution and judicial independence. Below I undertake an initial discussion of the issues, and leave an independent and thorough investigation to future studies.

Constitutional Survival. In the literature, there are two arguments for how constitutional rigidity affects the survival rate of the constitution. On the one hand, Burgess (1890) implies a negative linear relationship. He writes that the amendments clause affects 'whether the state shall develop with peaceable continuity or shall suffer alternations of stagnation, retrogression, and revolution' (Burgess 1890, 137). In other words, his argument is why replace a constitution when you can amend it? On the other hand, Elkins, Ginsburg and Melton (2009, 163-164) argue: 'Another strong predictor of longevity is amendment ease. As we have expected, the effect is non-linear. The predominant effect of the variable is to decrease the odds of replacement as flexibility increases... However, the square term yields a hazard ratio that is significant and higher than one, suggesting that extremely high values of flexibility are associated with an increased risk of death'. Why do Elkins, Ginsburg and Melton $(2009,100)$ expect a curvilinear relationship? Because 'Through these various channels, we expect that low thresholds for amendment will generally be associated with endurance. We add the qualifier 'generally' because of our uncertainty about the effects of extreme flexibility....'it seems reasonable to expect that extreme flexibility will yield unpredictable results with respect to life span'.

Both expectations indicate a relationship (linear or curvilinear) between constitutional rigidity and constitutional longevity. The difference between the two is that Burgess expects a linear negative relationship while Elkins et al. expect a generally negative relationship, but also a positive relationship in very low rigidity or 'extreme flexibility'. Their Figure 6.4 (p. 140), which describes 'Life Expectancy by Predicted Amendment Rate', indicates that the inflection is located exactly in the middle. ${ }^{20}$ At the theoretical level, I do not agree that the expectation is 'reasonable'. At the empirical level, they find that the inflection point corresponds to the middle level of values of amendment frequency, not the 'extreme values of flexibility'. But there are two reasons why we should doubt their conclusions. First, Elkins, Ginsburg and Melton (2009) use the frequency of amendments as an indicator for constitutional flexibility (the opposite of rigidity) as opposed to the constitutional amendment rules (see in the introduction of this article for Versteeg and Zackin's (2016) argument that amendment frequency is a better indicator). Secondly, they include all countries and all constitutions in their sample. Yet the constitution cannot be causally related to any dependent variable when there is no rule of law, which is the case in authoritarian regimes. It is plausible to assume that the negative relationship between the amendment rate and life expectancy of a constitution characterizes authoritarian regimes while the positive relationship (which is Burgess' prediction) is more likely to hold for democratic ones.

My dataset only includes data on constitutions that were in effect in 2013. To apply a Cox model, I would need to include all constitutions (both those in effect and those that are 'dead'). While there is a negative relationship between amendment rigidity and the age of a constitution, this relationship cannot speak to the life expectancy of a constitution. Some of these constitutions could be replaced tomorrow and others in a hundred years. If one focuses on the constitutions that have lasted more than a hundred years, three of them have high constitutional rigidity (above 1.1 - USA, Canada and Austria), and six of them low (below 0.9 - Netherlands, Belgium, Luxemburg, Norway, New Zealand and Great Britain). Some prima facie evidence would be in favor of Burgess (1890), but further research is necessary. It would require expanding the dataset of democratic constitutions to those not in effect today (and correlating the age of the placement with their constitutional rigidity calculated along the lines I propose in this article).

\footnotetext{
${ }^{20}$ Amendment flexibility appears to be "just right" at about 0.54 on our flexibility scale, which exactly corresponds to India's score on the measure' (Elkins et al. 2009, 140).
} 
Time Inconsistency. Another area related to constitutional rigidity is time inconsistency. Instead of considering amendment (in)frequency as a proxy for constitutional rigidity, Tsebelis (2017a) examined the difference between the actual amendment frequency and the one predicted on the basis of constitutional rigidity and named it 'time inconsistency'. The founders of the constitution use the amendment rules to lock the constitution and prevent amendments as long as the conditions of the amendment clause are not met. However, subsequent generations may find particular rules inappropriate for regulating their current political life and succeed in changing them. This is a form of intergenerational conflict: one generation locked the constitution and the next unlocked it. Tsebelis (2017a) found that time inconsistency is related to the size of the constitution: longer constitutions are revised more frequently than what their constitutional rigidity would suggest. However, he used crude indicators of constitutional rigidity (either the number of institutional veto players or the required majorities). The more precise measure of constitutional rigidity presented in this article may affect the results of his analysis. Further research using the index produced here is necessary.

Judicial Discretion. Finally, constitutional rigidity not only affects the frequency of constitutional revisions; it is also associated with the importance of constitutional courts in different countries. Since Cooter and Ginsburg's (1996) pathbreaking article on judicial discretion, the literature on judicial independence has flourished. Cooter and Ginsburg (1996) argued that judicial discretion will increase when judges are not afraid that they will be overruled, meaning that it will increase with the number of legislative veto players. They presented a brilliant (but limited) measure of judicial discretion: whether the courts alone (high discretion) or in co-operation with the legislature (medium discretion) had developed measures of strict liability for consumer product injuries. The default condition when the legislature develops the rules is classified as low discretion. Their empirical research corroborated their expectations. Today, a voluminous literature is discussing de jure (formal) and de facto (behavioral) judicial independence. Most of the literature considers Judicial Independence (JI) essential to constrain state power and make agreements credible (North and Weingast 1989), leading to efficient investment, growth and development (Acemoglu, Johnson and Robinson 2001; Barro 1997; Feld and Voigt 2003), and respecting human rights (Powell and Jeffrey 2009). Most of these studies investigate both democracies and non-democracies, because they examine whether JI consolidates democracy. The literature distinguishes between de jure independence measured with an index of multiple institutions (length of tenure, methods of appointment and removal; Keith (2002), Feld and Voigt (2003), La Porta et al. (2004)) and de facto independence measured by expert assessments (Howard and Carey (2004) or the Polity Index). Evaluations and comparisons of the approaches can be found in Rios-Figueroa and Staton (2014). However, the correlation between de jure and de facto JI is low, and researchers have even disputed the usefulness of the concept (Kornhauser 2002).

However, when we speak about JI it would be helpful to go back to Cooter and Ginsburg (1996) and base our analysis on the courts' discretion. In this case, we would be able to proceed in a more fruitful piecemeal way. The evidence in support of their proposition (that discretion increases with the number of legislative veto players) is usually restricted to ordinary legislation (see Tsebelis (2002) and Cooter and Ginsburg (1996) for developed countries, and Andrews and Montinola (2004) for developing countries). ${ }^{21}$

At least three direct inferences can be made on the basis of their approach. First, high discretion is a necessary but not sufficient condition for JI. Indeed, if a court has no discretion, it will not be independent, but if it has high discretion, it still may not be independent. Secondly, the level of discretion will depend on the procedure by which the courts can be over-ruled. Therefore, it will in principle be different for constitutional vs. ordinary courts. For ordinary courts (more accurately for statutory interpretations of any court), the determinant factor will

\footnotetext{
${ }^{21}$ In legal terms, statutory interpretation is judicial decisions based on laws, not the constitution.
} 
be legislative over-rule (that is, the size of a country's legislative core), while for constitutional decisions the decisive factor will be the constitutional core (as defined in Appendix II). Thirdly, we have to become more precise about which actors are relevant for which definitions of JI. This is not an issue discussed often in the literature. Peretti (2002) uses this argument to claim that there are so many actors that the judiciary could be independent from, meaning that there is no JI (from any of them). I believe the main actor from which we should be considering JI is the current government, and this should be explicitly asked of the experts who assess JI. We should identify the cases in which the judiciary makes decisions that conflict with those of the current government. Constitutionally over-ruling old laws is not necessarily an indication of JI; it could be a sign that the laws have become obsolete. As far as constitutional courts are concerned, we should be able to identify the number of times the courts have considered the laws of the current government unconstitutional.

Assuming the constitutional courts do not want to be over-ruled, they will exercise discretion proportionally to the size of the constitutional core. Therefore, judicial discretion will be proportional to the index used in this article. ${ }^{22}$ Judicial discretion is a necessary but not sufficient condition for JI. This means the relationship between the two variables will be heteroskedastic (just like the relationship between constitutional rigidity and amendment frequency explored in this article). The best way to measure JI is to find cases of courts over-ruling the government in power.

The only article I have seen along these lines is Santoni and Zucchini (2004), who examined the Italian Constitutional Court from 1956-1992 and found that the frequency with which it disputes the constitutionality of laws increases when the constitutional core increases (Santoni and Zucchini 2004). In their case, the core increases as a function of the policy positions of the parties necessary to participate in a procedure of constitutional revision. Santoni and Zucchini focus on the case of Italy alone (and do not test for heteroskedasticity). In order to replicate their analysis at the cross-national level, we need the indicator of constitutional rigidity presented in this article, along with decisions of constitutional courts in different countries rejecting laws proposed by the government in power. I would expect to observe a heteroskedastic relationship between judicial discretion and the number of judicial decisions related to the unconstitutionality of current government laws. This is another issue delegated to further research. Consequently, the constitutional rigidity index calculated in this article can be used in various areas of constitutional and judicial studies.

Supplementary material. Online appendices are available at https://doi.org/10.1017/S0007123420000411.

Data Availability Statement. Data replication files are available in Harvard Dataverse at: https://doi.org/10.7910/DVN/ VSESCP.

Acknowledgements. The majority of this work was done while I was a Visiting Fellow at the Kellogg Institute. I would like to thank the Kellogg Institute and the University of Michigan for financial support. I would also like to thank the following colleagues who provided amendment significance ratings: Şener Aktürk, Eduardo Alemán, Rod Alence, Abel Djassi Amado, Ana Catalina Arango Restrepo, Jorge Baquerizo, Kamila Bezubik, Agnieszka Bień-Kacała, Eszter Bodnár, Catarina Santos Botelho, Mario Cajas, Cláudio Gonçalves Couto, Jesse Crosson, Javier Duque Daza, Boniface Dulani, Arolda Elbasani, Alan Fenna, Martina Flick, Claudio Fuentes, Venelin I. Ganev, Aris Georgopoulos, Marco Giuliani, Magnus Hagevi, Gábor Halmai, Allen Hicken, Giuseppe Ieraci, Christian Jensen, Aida Just, Yannis Karagiannis, Dean Knight, Thomas Koelble, Viktoriia Kolesnyk, Amie Kreppel, Ming-Sung Kuo, Nikolas Kyriakou, Tomáš Lalík, Mahendra Lawoti, Sokol Lleshi, Małgorzata Lorencka, Emmett Macfarlane, Lára Magnúsardóttir, Mikko Mattila, Robert Mattes, Milan JN Meetarbhan, Woojin Moon, Erika Moreno, Juan Andres Moraes, Wolfgang Claudius Müller, Malkhaz Nakashidze, Noah Nathan, Gabriel Negretto, Joakim Nergelius, Bertil Emrah Oder, Eoin O’Malley, Reijer Passchier, Darko Pavlovski, Bjørn Erik Rasch, Julio Ríos-Figueroa, Tatiana Rizova, Juan Carlos Rodríguez-Cordero, Matt Ryan, Anna Rytel-Warzocha, Camilo Emiliano Saavedra Herrera, Sebastian Saiegh, Pascal Sciarini, Aqil Shah, Ulrich Sieberer, Güneş Murat Tezcür, Brian Turner, Wilson Tay Tze Vern, Arta Vorpsi, Jarle Weigård, Wojtek Mojski, Oya Yeğen, Francesco Zucchini. I would also like to thank Nikos Alivizatos, Rogerio Arantes, Paolo Carozza, Eric Chang, Michael Coppedge, Julio Ríos-Figueroa,

\footnotetext{
${ }^{22}$ Something that Hayo and Voigt (2016) would have liked to do, but did not because (among other things) of the lack of reliable constitutional rigidity indicators, as discussed in the introduction to this article.
} 
Barbara Koremenos, Scott Mainwaring, Kevin Quinn, Kaare Strom and Vassilis Tzevelekos for critical comments. I thank Tom Ginsburg for providing me with the data on amendments, and Richard Albert for providing me the means to collect data on the significance of amendments through the blog site ICONnect. I am indebted to Jesse Crosson, Joe Klaver, Julia Maynard and Hyeon Young Ro for excellent research assistance.

\section{References}

Acemoglu D, Johnson, S and Robinson, J (2001) The colonial origins of comparative development: an empirical investigation. The American Economic Review 91(5), 1369-1401.

Achen CH (2001) Why Lagged Dependent Variables Can Suppress the Explanatory Power of Other Independent Variables. Presented at the Annual Meeting of the Midwest Political Science Association, April 2000.

Albert R (2014) The structure of constitutional amendment rules. Wake Forest Law Review 49, 913-976.

Albert R (2015) The unamendable core of the United States constitution. In Koltay A (ed.), Comparative Perspectives on the Fundamental Freedom of Expression. Wolters Kluwer Ltd., pp. 13-40.

Albert R (2019) Constitutional Amendments: Making, Breaking, and Changing Constitutions. Oxford: Oxford University Press.

Anckar D and Karvonen L (2002) Constitutional Amendment Methods in the Democracies of the World. Trabalho apresentado no XIII Nordic Political Science Congress, Aalborg, Denmark, pp. 15-17.

Andrews JT and Montinola GR (2004) Veto players and the rule of law in emerging democracies. Comparative Political Studies 37(1), 55-87.

Barro RJ (1997) Determinants of Economic Growth: A Cross-Country Empirical Study. Cambridge, MA: MIT Press.

Bucur C and Rasch BE (2019) Institutions for amending constitutions. In Congleton RD, Grofman B and Voigt S (eds), The Oxford Handbook of Public Choice. New York: Oxford University Press, pp. 1-23.

Burgess JW (1890) Political Science and Constitutional Law, 2 vols. Boston and London: Ginn \& Company.

Contiades X and Fotiadou A (2016) The determinants of constitutional amendability: amendment models or amendment culture? European Constitutional Law Review 12(1), 192-211.

Cooter R and Ginsburg T (1996) Comparative judicial discretion: an empirical test of economic models. International Review of Law and Economics 16(3), 295-313.

Crosson JM (2019) Stalemate in the states: agenda control rules and policy output in American legislatures. Legislative Studies Quarterly 44(1), 3-33.

Dixon R (2011) Constitutional amendment rules: a comparative perspective. In Dixon R and Ginsburge T (eds), The Research Handbook in Comparative Constitutional Law. Northhampton, MA: Elgar Publishing, 96-111.

Dixon R (2018) Constitutional rights as bribes. Connecticut Law Review 50(3), 767-818.

Dixon R (2019) Constitutional design deferred. In Landau D and Lerner H (eds), Comparative Constitution Making. Northampton, MA: Edward Elgar Publishing, pp. 165-185.

Dixon R and Baldwin G (2019) Globalizing constitutional moments? A reflection on the Japanese article 9 debate. The American Journal of Comparative Law 67(1), 145-176.

Dixon R and Landau D (2018) Tiered constitutional design. The George Washington Law Review 86(438), 438-512.

Dixon R and McManus, B (2018) Detaining non-citizens: political competition and weak v. strong judicial review. Virginia Journal of International Law 57(3), 591-620.

Elkins Z, Ginsburg T and Melton J (2009) The Endurance of National Constitutions. Cambridge: Cambridge University Press.

Elster J (2000) Ulysses Unbound: Studies in Rationality, Precommitment, and Constraints. Cambridge: Cambridge University Press.

Feld L and Voigt S (2003) Economic growth and judicial independence: cross country evidence using a new set of indicators. European Journal of Political Economy 19(3), 497-527.

Ferejohn J (1995) The politics of imperfection: the amendment of constitutions. In Levinson S (ed.), Responding to Imperfection: The Theory and Practice of Constitutional Amendment. Princeton, NJ: Princeton University Press, pp. 501-530.

Finer H (1949) The Theory and Practice of Modern Government. New York: Henry Holt and Company.

Fruhstorfer A and Hein M (2016) From post-socialist transition to the reform of political systems? Comparing constitutional politics in Central and Eastern Europe. In Fruhstorfer A and Hein M (eds), Constitutional Politics in Central and Eastern Europe. Wiesbaden: Springer Fachmedien Wiesbaden, pp. 547-576.

Ginsburg T and Melton J (2015) Does the constitutional amendment rule matter at all? Amendment cultures and the challenges of measuring amendment difficulty. International Journal of Constitutional Law 13(3), 686-713.

Goertz G (2017) Multimethod Research, Causal Mechanisms, and Case Studies: An Integrated Approach. Princeton, NJ: Princeton University Press.

Goertz G and Starr H (2002) Necessary Conditions: Theory, Methodology, and Applications. Lanham, MD: Rowman \& Littlefield.

Hayo B and Voigt S (2016) Explaining constitutional change: the case of judicial independence. International Review of Law and Economics 48, 1-13. 
Howard RM and Carey HF (2004) Is an independent judiciary necessary for democracy? Judicature: The Journal of American Judicature Society 87(6), 284-292.

Howell W et al. (2000) Divided government and the legislative productivity of Congress. Legislative Studies Quarterly, 285312 XXV(2), 285-312.

Jackson V (2016) Positive obligations, positive rights, and constitutional amendment. In Kahana T and Scolnicov A (eds), Boundaries of State, Boundaries of Rights: Human Rights, Private Actors, and Positive Obligations. Cambridge: Cambridge University Press, 109-128.

Kalyvas A (2012) Constituent power. In Ophir A and Stoler AL (eds), Political Concepts: A Critical Lexicon. New York: Fordham University Press, 87-117.

Kay RS (2018) Formal and informal amendment of the United States constitution. The American Journal of Comparative Law 66(Suppl_1), 243-268.

Keith LC (2002) Constitutional provisions for individual human rights: are they more than mere 'window dressing'? Political Research Quarterly 55(1), 111-143.

Klug H (2015) The constitution in comparative perspective. In Tushnet M, Graber MA and Levinson S (eds), The Oxford Handbook of the U.S. Constitution. New York: Oxford University Press, pp. 943-966.

Kornhauser L (2002) Is judicial independence a useful concept? In Burbank SB and Friedman B (eds), Judicial Independence at the Crossroads: An Interdisciplinary Approach. Thousand Oaks, CA: SAGE Publications, pp. 45-55.

Landemore $\mathbf{H}$ (2016) What Is a good constitution? Assessing the constitutional proposal in the Icelandic Experiment. In T Ginsburg and AZ Huq (eds), Assessing Constitutional Performance, Comparative Constitutional law and Policy. New York: Cambridge University Press, pp. 71-98.

Lane J (2011) Constitutions and Political Theory. Manchester: Manchester University Press.

La Porta R et al. (2004) Judicial checks and balances. Journal of Political Economy 112(2), 445-470.

Lijphart A (1999) Patterns of Democracy: Government Forms and Performance in Thirty-six Democracies. New Haven, CT: Yale University Press.

Lorenz A (2005) How to measure constitutional rigidity: four concepts and two alternatives. Journal of Theoretical Politics 17 (3), 339-361.

Lorenz A (2016) How differently actors cope with demanding constitutional amendment rules: two types of constitutional politics in federal democracies. Regional \& Federal Studies 26(5), 729-748.

Lutz S (1994) Toward a theory of constitutional amendment. American Political Science Review 88(2), 355-370.

Marshall MG (2016) Polity IV Project: Political Regime Characteristics and Transitions, 1800-2013. Vienna, VA: Center for Systemic Peace. Available from http://www.systemicpeace.org/polity/polity4.htm (accessed 17 July 2018).

Marshfield JL (2017) Courts and informal constitutional change in the states. New England Law Review 51, $453-511$.

Marshfield JL (2018) The amendment effect. Boston University Law Review 98(1), 55-126.

Martin C (2017) The legitimacy of informal constitutional amendment and the reinterpretation of Japan's war powers. Fordham International Law Journal 40(2), 427-522.

McGreevy J (2003) Catholicism and American Freedom. New York: W.W. Norton.

Merrill TW (2018) Interpreting an unamendable text. Vanderbilt Law Review 71(2), 547-602.

Negretto GL (2012) Replacing and amending constitutions: the logic of constitutional change in Latin America. Law and Society Review 46(4), 749-779.

North D and Weingast B (1989) Constitutions and commitment: the evolution of institutions governing public choice in seventeenth-century England. The Journal of Economic History 49(4), 803-832.

Peretti TJ (2002) Does judicial independence exist? The lessons of social science research. In Burbank SB and Friedman B (eds), Judicial Independence at the Crossroads: An Interdisciplinary Approach. Thousand Oaks, CA: SAGE Publications, pp. 103-133.

Powell EJ and Jeffrey K (2009) Domestic judicial institutions and human rights treaty violations. International Studies Quarterly 53(1), 149-174.

Rasch BE and Congleton RD (2006) Amendment procedures and constitutional stability. In Congleton RD and Swedenborg B (eds), Democratic Constitutional Design and Public Policy: Analysis and Evidence. Cambridge, MA: MIT Press, pp. 536-561.

Rios-Figueroa J and Staton JK (2014) An evaluation of cross-national measures of judicial independence. The Journal of Law, Economics, and Organization 30(1), 104-137.

Rivera MV (2019) Constitutional amendment (non)difficulty in Mexico. In Albert R, Bernal C and Benvindo JZ (eds), Constitutional Change and Transformation in Latin America. London: Bloomsbury Publishing Plc, 56-76.

Sajó A and Uitz R (2017) The Constitution of Freedom: An Introduction to Legal Constitutionalism. Oxford: Oxford University Press.

Santoni M and Zucchini F (2004) Does policy stability increase the constitutional court's independence? The case of Italy during the First Republic (1956-1992). Public Choice 120(3-4), 149-401.

Schneier EV (2006) Crafting Constitutional Democracies: The Politics of Institutional Design. Oxford: Rowman \& Littlefield.

Tsebelis G (2002) Veto Players: How Political Institutions Work. Princeton, NJ: Princeton University Press.

Tsebelis G (2017a) The time inconsistency of long constitutions: evidence from the world. European Journal of Political Research 56(4), 820-845. 
Tsebelis G (2017b) Compromesso astorico: the role of the Senate after the Italian constitutional reform. Italian Political Science Review/Rivista Italiana di Scienza Politica 47(1), 87-104.

Tsebelis G (2018) Veto players and constitutional change: can Pinochet's constitution be unlocked? Política y Gobierno 25(1), 3-30.

Tsebelis G and Nardi DJ (2016) A long constitution is a (positively) bad constitution: evidence from OECD countries. British Journal of Political Science 46(2), 457-480.

Tsebelis G (2020) "Replication Data for: Constitutional Rigidity Matters: A Veto Players Approach", https://doi.org/10.7910/ DVN/VSESCP, Harvard Dataverse, V1, UNF:6:ukBnAOoRt3rxpqTAiFZwMw== [fileUNF].

Versteeg M and Zackin E (2016) Constitutions unentrenched: toward an alternative theory of constitutional design. American Political Science Review 110(4), 657-674.

Weingast BR (2005) The constitutional dilemma of economic liberty. Journal of Economic Perspectives 19(3), 98-108.

Yokodaido S (2019) Constitutional stability in Japan not due to popular approval. German Law Journal 20(2), $263-283$.

Cite this article: Tsebelis G (2022). Constitutional Rigidity Matters: A Veto Players Approach. British Journal of Political Science 52, 280-299. https://doi.org/10.1017/S0007123420000411 